\title{
FRONTAL SINUS OBLITERATION USING AUTOGENOUS ABDOMINAL FAT VERSUS AUTOGENOUS BONE: RANDOMIZED CONTROL CLINICAL TRIAL
}

\author{
Mostafa Talaat El Gengehy*, Sherif Ali $^{*}$ and Ahmed Talaat Temerek**
}

\begin{abstract}
Aim: The aim of this study was to compare postoperative complications and donor site morbidity following frontal sinus obliteration with autogenous abdominal fat compared to autogenous bone harvested from anterior iliac crest.

Research question: Will frontal sinus obliteration with autogenous abdominal fat result in less sinus and donor site complications compared to sinus obliteration with autogenous bone harvested from anterior iliac crest?

Materials and Methods: This was a randomized controlled trial conducted on 10 patients with frontal sinus anterior wall fracture indicating frontal sinus obliteration. In group I, the sinuses were obliterated with autogenous abdominal fat. While in group II, the sinuses were obliterated with autogenous bone harvested from anterior iliac crest. Sinus postoperative assessment was performed clinically and radiologically to evaluate postoperative complications (local sinus pathology including sinusitis, mucocele, pyomucocele, wound infection, wound dehiscence, esthetic deformity). Donor site morbidity was assessed for the presence of any complication, postoperative pain intensity and duration.
\end{abstract}

Results: Both groups showed no postoperative sinus complications. Group II showed donor site higher pain intensity and longer pain duration with statistically significant difference when compared to group I.

Conclusions: Abdominal autogenous fat seemed to be a better frontal sinus obliteration material compared to autogenous bone harvested from iliac crest, thanks to its lower donor site morbidity. However, we recommend further investigations with longer follow up periods to elucidate more about this topic.

KEYWORDS: Frontal sinus obliteration, Autogenous abdominal fat, Autogenous bone.

* Lecturer, Oral and Maxillofacial Surgery Department, Faculty of Dentistry, Cairo University, Cairo, Egypt.

** Lecturer, Oral and Maxillofacial Surgery Department, Faculty of Dentistry, South Valley University, Qena, Egypt. 


\section{INTRODUCTION}

Incidence of frontal sinus fractures is uncommon accounting for 5-12\% of all facial fractures ${ }^{1,2}$. Numerous classification systems have been used. They are mainly based on involved walls, nasofrontal duct patency, fracture pattern, displacement, comminution, involvement of nasoorbitoethmoidal complex, and cranial fossa. However, elaboration of detailed classifications with multiple subdivisions does not significantly add in frontal sinus fractures management ${ }^{3-6}$. The goals of frontal sinus injuries management are restoring facial esthetics, function, and preventing complications. Treatment options range from conservative observation, reduction and fixation, sinus obliteration, and cranialization. Management of frontal sinus injuries is mainly dependent on: anterior wall, posterior wall, and nasofrontal duct ${ }^{1,4,8-12}$.

Anterior sinus wall is the most common site affected by injury, either isolate or with the posterior wall. Isolated anterior table fractures represent about $33 \%$ of frontal sinus fractures. Treatment decision is dependent on the degree of disruption in cosmetics and/or frontonasal duct 1,7,13. Frontal sinus health depends totally on the patency of its duct and ostium, subsequently direct trauma that results in interruptions of the outflow will jeopardize the sinus function, indicating frontal sinus obliteration ${ }^{6,13,14}$.

Frontal sinus obliteration aims to prevent post rauma complications as infection and cystic degeneration of the lining. In such procedure, the sinus mucosa is removed to prevent epithelial pathological proliferation, and the residual dead space is obliterated ${ }^{15}$. Various materials have been used for sinus obliteration ${ }^{16-20}$. Autogenous materials are the preferable choice, considering their favorable longterm outcomes, low material cost and predictability in the repair of larger defect ${ }^{8,16}$. Furthermore, they are highly recommended over bone substitutes in contaminated fractures, and acute injuries ${ }^{4}$.

Autogenous bone, and fat have been widely used for sinus obliteration 8, 18, 21-22. Autogenous bone can be harvested from different donor sites but those of common use in frontal sinus grafting are the iliac crest bones ${ }^{23}$. It has a relatively direct approach and can supply adequate volume of corticocancellous or cancellous bone that is rich in pluripotent or osteogenic precursor cells which support osteogenesis to fill the dead space, nevertheless, donor site morbidity following grafting with iliac bone should be considered in the treatment plan ${ }^{24-26}$. Autogenous fat has been widely used for frontal sinus obliteration. The main advantages of autogenous fat are easy of harvest and handling. It proved its reliability as obliteration material. It successfully acts as a barrier between the neurocranium and upper airways, preventing retrograde infection $9,8,18,21,27$.

Even though autogenous fat and bone have been widely used in frontal sinus obliteration, no randomized controlled clinical trial has been previously conducted to compare the two techniques.

\section{Research question}

Will frontal sinus obliteration with autogenous abdominal fat result in less sinus and donor site complications compared to sinus obliteration with autogenous bone harvested from anterior iliac crest?

\section{METHODS}

This was a parallel-group randomized controlled trial conducted from September 2016 to November 2018 on 10 patients with frontal sinus fractures indicating sinus obliteration. Patients were allocated randomly into 2 groups. Group I, formed of 5 patients with sinuses obliterated using autogenous abdominal fat. While in group II, with same number of patients but with sinuses obliterated using autogenous bone harvested from anterior iliac crest.

Patients were recruited from the out-patient clinic, Department of Oral and Maxillofacial Surgery, Faculty of Dentistry, Cairo University; and Cranio-Maxillofacial Surgery Department, Nasser Institute hospital. Patients were selected according to the following criteria: frontal sinus anterior wall fracture indicating frontal sinus 
obliteration; medically stable and free from any systemic condition contraindicating the procedure; patients with posterior wall fractures (indicating cranialization) were excluded.

Frontal sinus was accessed via bicoronal flap or existing lacerations (figure 1). To expose the frontal sinus cavity, anterior wall fracture fragments were temporally removed and preserved in normal saline. The sinus cavity was debrided with bone curettes and bur under copious amount of irrigation. The nasofrontal duct was then sealed with pericranium. The frontal sinus was obliterated with the grafting materials (autogenous abdominal fat for group I, autogenous bone for group II).

Abdominal fat was harvested for sinus obliteration in group I. The proposed site was injected with the vasoconstrictor. The fat was exposed using skin midline transverse incision about $2-3 \mathrm{~cm}$ below the umbilicus. The desired amount was harvested, and incision was sutured (figure 2). While in group II, autogenous bone was harvested from anterior iliac crest. The proposed site was injected with the vasoconstrictor. The skin overlying the crest was retracted medially, and the skin incision was performed. Dissection was then carried out till the periosteum, which was sharply incised to expose the iliac crest. The desired amount of bone was harvested, and incision was sutured (figure 3). The bone was then grinded and used to fill the sinus. After sinus obliteration, anterior sinus wall was reconstructed afterwards with titanium mesh, bone fragment reduction and fixation, or both (figure 4). Finally, the incision was sutured in layer. Standard postoperative care was done for all patients.

Patient postoperative assessment was mainly concerned with frontal sinus and donor site. Sinus postoperative assessment was performed clinically (at 4 weeks, 3, 6, and 12 months), and radiologically using CT (immediate postoperatively, and after 12 months) (Fig. 5,6) to evaluate postoperative complications (local sinus pathology including sinusitis, mucocele, pyomucocele, wound infection, wound dehiscence, esthetic deformity). Donor site was evaluated to assess the presence of any complication. Additional assessment was performed to assess postoperative pain intensity at the donor site after one week using visual analog scale of 0 to 10 range $(0=$ no pain, $10=$ worst pain $)$, and by asking the patient about pain duration (How long did you experience pain in donor site?).

\section{Statistical analysis}

Statistical analysis was performed using SPSS (Statistical package for the social sciences- IBM® SPSS $®$ Statistics Version 20 for Windows, IBM Corp., Armonk, NY, USA). Quantitative data were represented as mean \pm standard deviation, and Mann-Whitney $\mathrm{U}$ test was used to compare variables between the two groups. Qualitative data were represented as percentage or frequency, and Fisher's exact test was used to compare variables between the two groups. The results were considered statistically significant if the $\mathrm{p}$ value was less than 0.05 .

\section{RESULTS}

This study was conducted on 10 patients (7 males, 3 females) with mean age of $34.9 \pm 9.2$ years. The mean age was $33.8 \pm 9.5$ years for group I, and $41.4 \pm 7.8$ years for group II. The most common cause of injury was motor vehicle accident (70\%), other causes include fall from height and interpersonal violence. No local sinus pathology was observed in both groups. Both groups showed no wound dehiscence or infection. All cases showed no contour changes till the end of follow up period. Postoperative pain at donor site was higher in autogenous iliac bone group (group II) when compared to autogenous fat group (group I) $(5.2 \pm 0.84,3.4 \pm 1.1$ respectively). Pain duration was higher in group II when compared to group I (7.2 $\pm 1.1,5.2 \pm 0.8$ days respectively). There was statistically significant difference between the 2 groups ( $\mathrm{P}$ value $<0.05)$ in pain intensity and duration (figure 5). Group I showed no donor site complications other than pain, while one patient in group II showed gait disturbance for 2 weeks (table 1) (Fig. 7). 
TABLE (1) Showing postoperative frontal sinus and donor site complications as number (percentage) for qualitative data, and mean \pm standard deviation for quantitative data.

\begin{tabular}{|c|c|c|c|c|}
\hline \multicolumn{2}{|c|}{ Outcome (unit) } & Group I & Group II & P value \\
\hline \multirow{2}{*}{} & Local pathology (number of patients) & $0(0 \%)$ & $0(0 \%)$ & $>0.05$ \\
\cline { 2 - 5 } & Wound dehiscence (number of patients) & $0(0 \%)$ & $0(0 \%)$ & $>0.05$ \\
\cline { 2 - 5 } & Wound infection (number of patients) & $0(0 \%)$ & $0(0 \%)$ & $>0.05$ \\
\cline { 2 - 5 } & Esthetic deformity (number of patients) & $0(0 \%)$ & $0(0 \%)$ & $>0.05$ \\
\cline { 2 - 5 } & Pain intensity (0-1 score) & $3.4 \pm 1.1$ & $5.2 \pm 0.84$ & $<0.05^{*}$ \\
\cline { 2 - 5 } & Complication (number of patients) & $5.2 \pm 0.8$ & $7.2 \pm 1.1$ & $<0.05^{*}$ \\
\hline
\end{tabular}

* Significant difference between the 2 groups

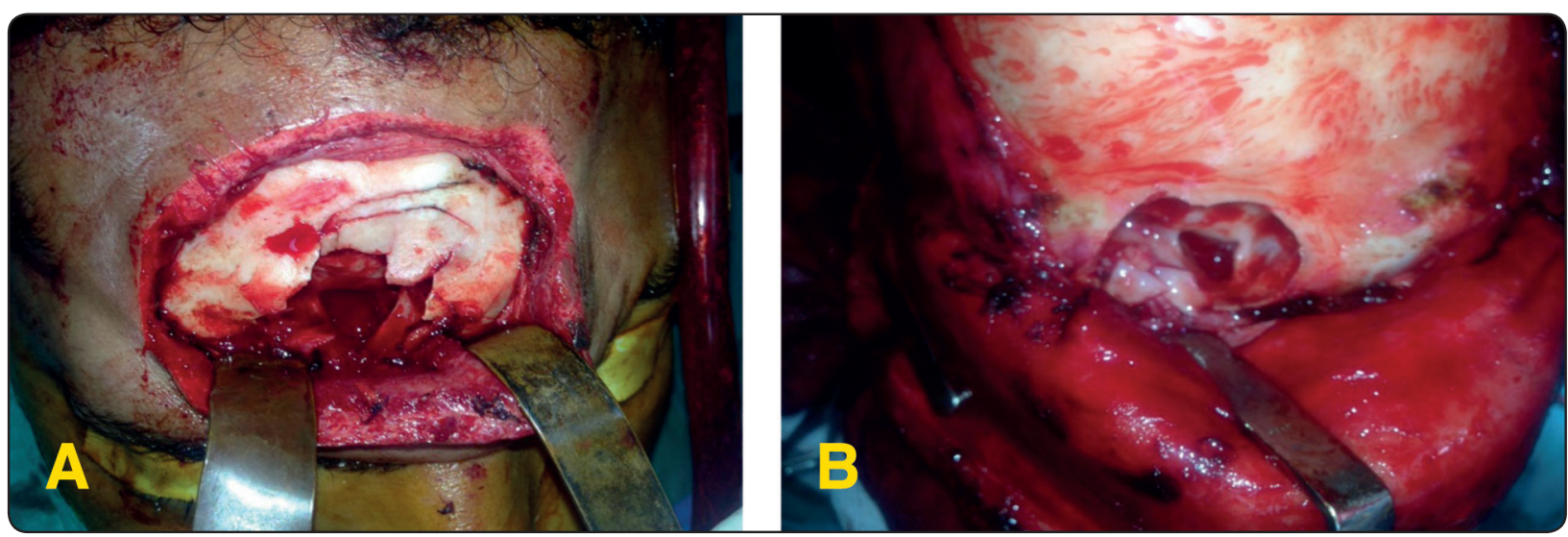

Fig. (1) A. Access to frontal sinus through existing laceration. B. Access to frontal sinus through bicoronal incision.

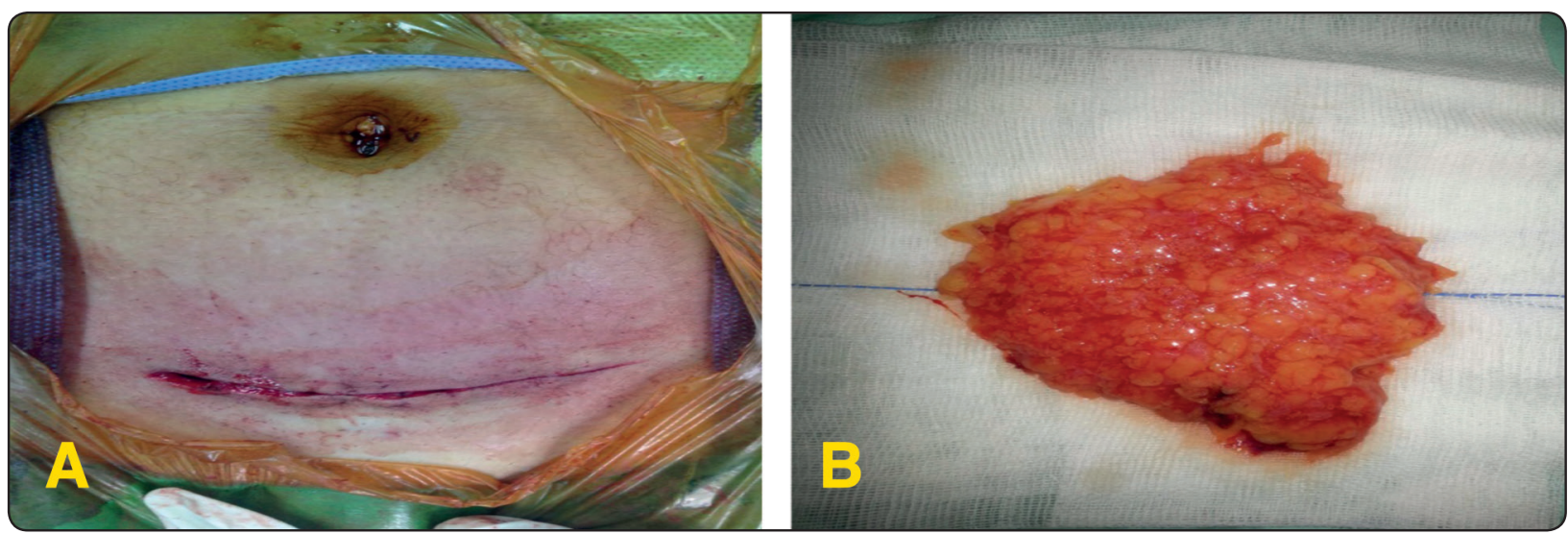

Fig. (2) Autogenous abdominal fat harvesting. A. Skin mid line transverse incision. B. Harvested abdominal fat. 


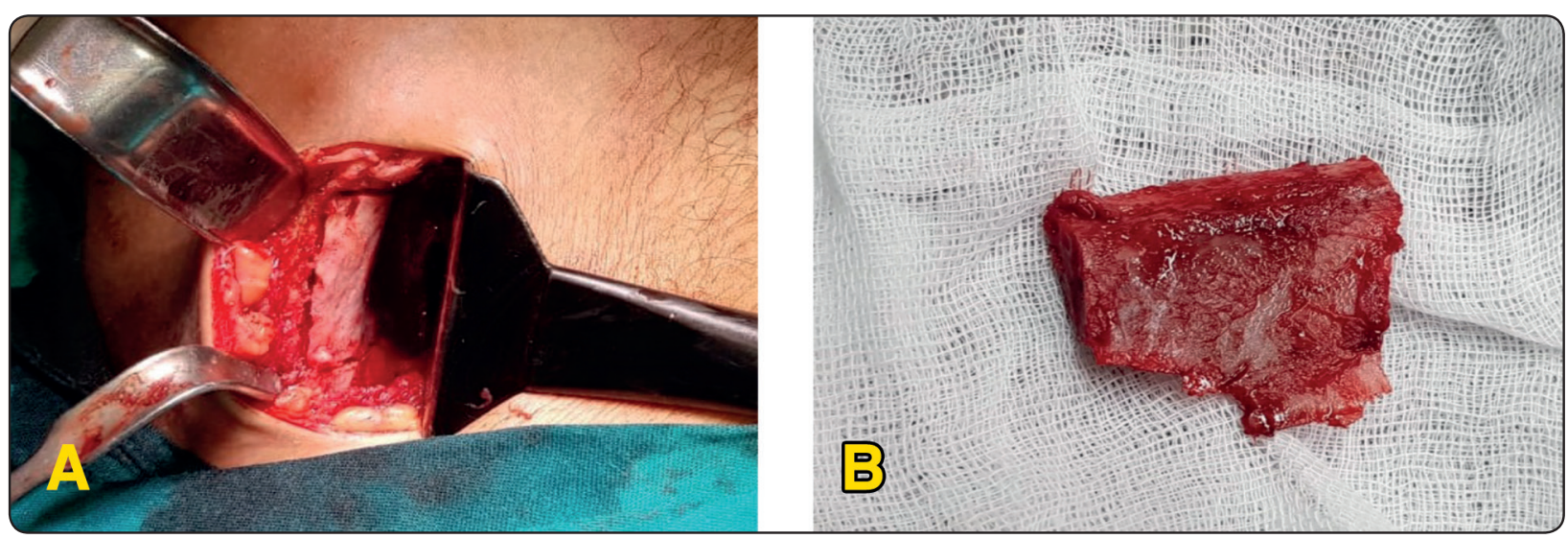

Fig. (3) Autogenous bone harvesting. A. Skin incision and exposure of iliac bone. B. Harvested iliac bone.

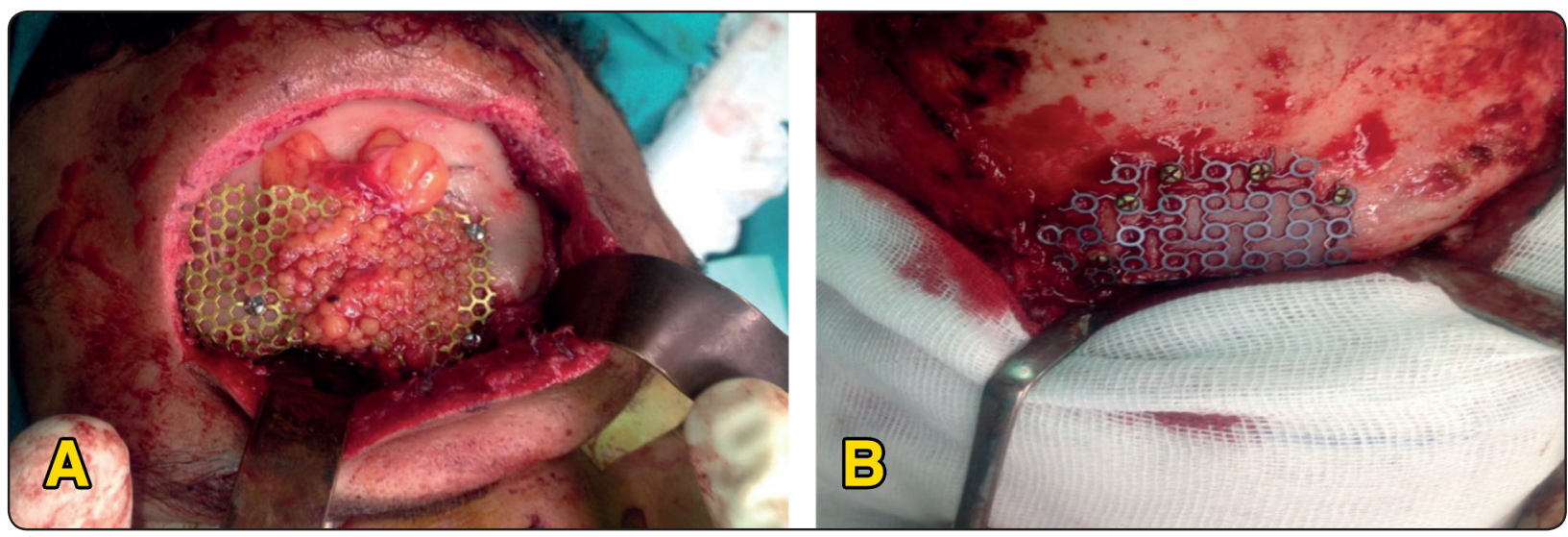

Fig. (4) A. Frontal sinus obliteration using fat. B. Frontal sinus obliteration using iliac bone.

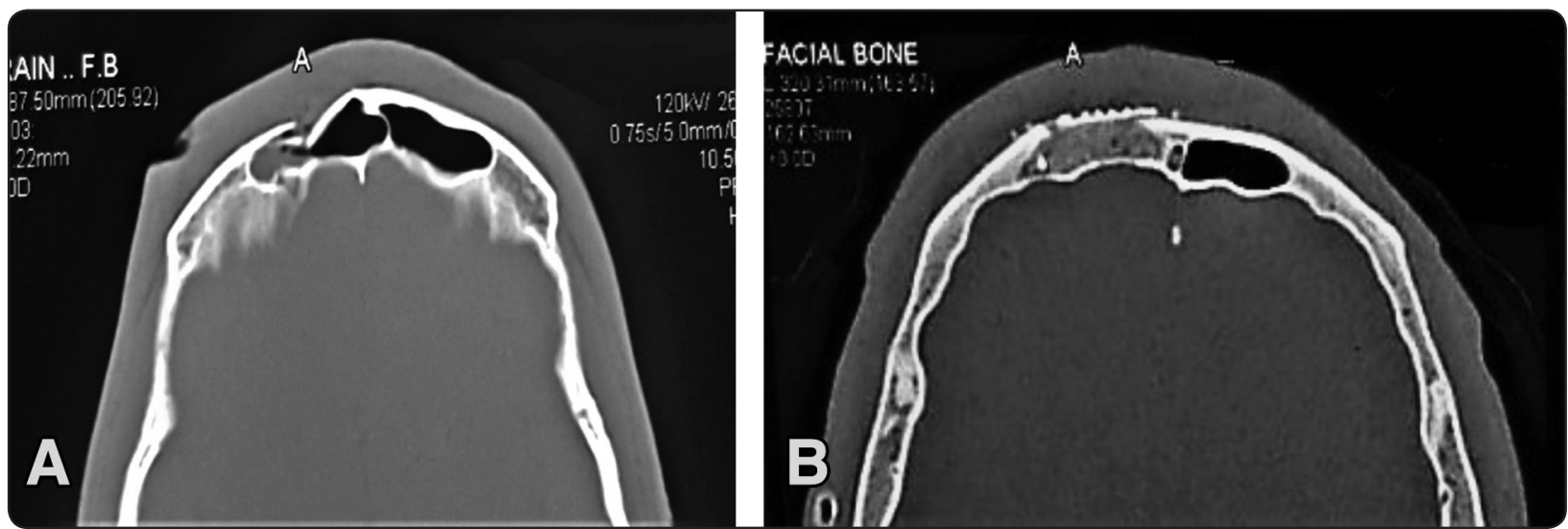

Fig. (5) A. Preoperative CT of Fractured Lt frontal sinus. B Postoperative frontal sinus obliteration using iliac bone. 


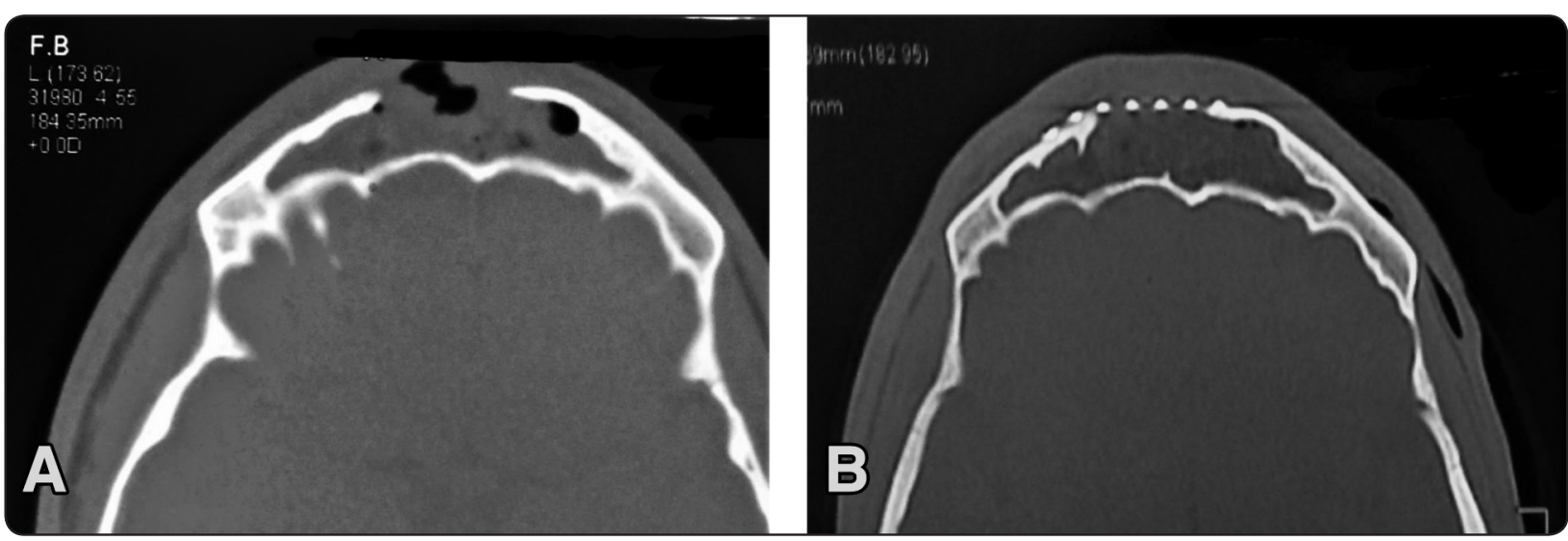

Fig. (6) A. Preoperative CT of Fractured frontal sinus B. Frontal sinus obliteration using fat.

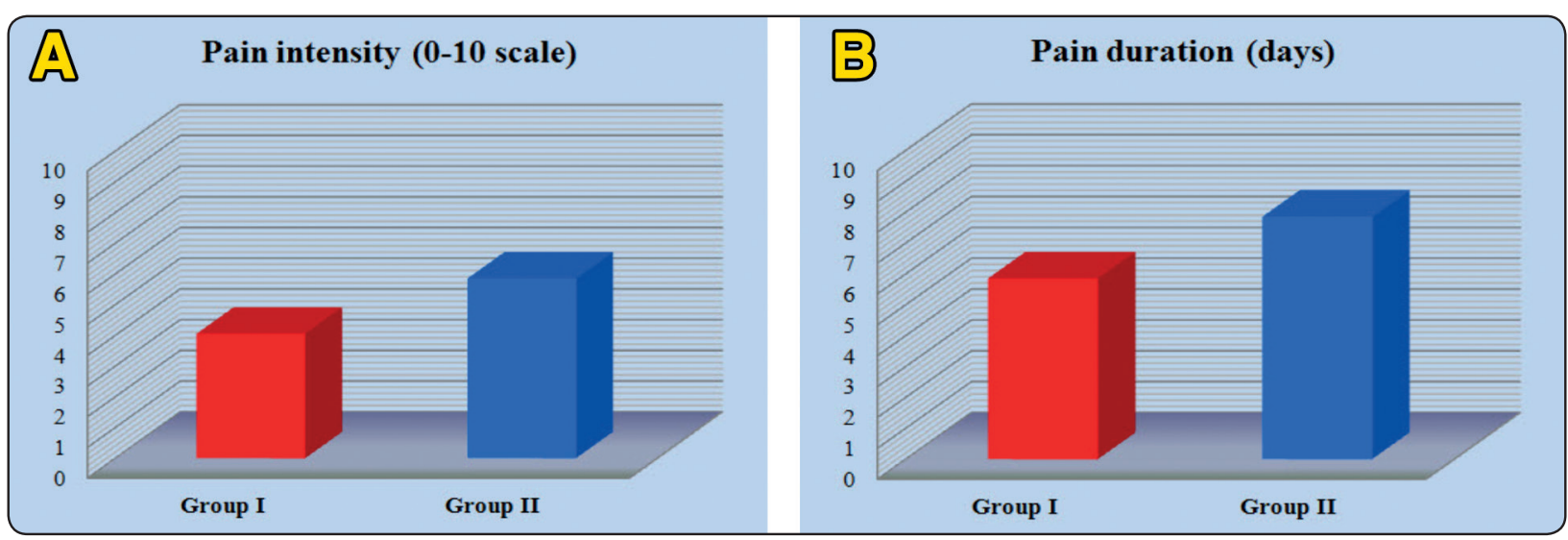

Fig. (7) Bar charts showing donor site postoperative pain. A. Pain intensity. B. Pain duration.

\section{DISCUSSION}

Frontal sinus trauma possesses a special clinical situation particularly when combined with nasofrontal duct obstruction as this may result in a significant morbid sequel. Treatment options include clinical and radiographic observation with no intervention, fractured segments open reduction and internal fixation, sinus cavity obliteration, cranialization, ablation and osteoneogenesis. Recently, it is well agreed that frontal sinus obliteration is the recommended treatment in such cases, demonstrating a proved role in avoiding common complications such as cystic degeneration in the form of mucocele and mucopyocele or infection in the form of meningitis, brain abscess or osteomyelitis ${ }^{28,29}$. This study aimed to assess frontal sinus obliteration with autogenous abdominal fat compared to autogenous bone.

Cancellous bone harvested from iliac crest has been widely used for frontal sinus obliteration and have been considered to be the best grafting material 22. Donald and Ettin ${ }^{30}$ in an experimental study suggested the use of autogenous bone instead of fat in comminuted fractures. This was attributed to the fat volume loss, resulting in mucosal ingrowths and mucocele formation. Moreover, it is supposed that the use of autogenous bone promotes bone formation leading to gradual ossification ${ }^{2,8,23,30}$.

To the contrary, numerous studies approved autogenous fat as a reliable obliteration material. It is 
considered as the most commonly used material ${ }^{3,}$ ${ }^{22}$. Bergara and Itoiz introduce in an experimental study the use of autogenous fat for obliterating the frontal sinus. They postulated that fat graft either vascularized or fibrosed would resist infection. They showed that thorough removal of the sinus mucosal lining with implanting adipose tissue is a viable option to prevent the regrowth of the mucoperiosteum ${ }^{31-33}$. Then clinical and experimental studies by Montgomery et al confirmed that autogenous fat is a reliable obliteration material with about $100 \%$ survival rate ${ }^{34-36}$. Zonis et al reported $3 \%$ failure rate with autogenous fat frontal sinus obliteration ${ }^{37}$. The largest series was conducted by Hardy and Montgomery ${ }^{38}$ and reported a complication rate of $18 \%$ in 250 patients. Donor site complications were $5.2 \%$, infection and necrosis was $3 \%$, while incidence of chronic sinusitis was $3 \%{ }^{38}$. Weber et al MRI radiographic studies ${ }^{18,21}$ on fat obliterated sinuses revealed that the grafted fat volume decrease with time, with half-life of 15.4 months. More than $50 \%$ of the patient showed less than $20 \%$ remaining fat. Yet, they recommended autogenous fat as a ahighly effective method for frontal sinus obliteration, with $90 \%$ success rate ${ }^{18,21}$.

Our study showed comparable results for autogenous fat and bone regarding sinus postoperative complications. Abdominal autogenous fat showed significantly lower pain intensity, significantly shorter pain duration, with lower donor site morbidity compared to autogenous bone harvested from anterior iliac crest. This result is in accordance with Mickel et al ${ }^{27}$ experimental study which showed that both techniques are effective in frontal sinus obliteration, with significant donor site morbidity for autogenous bone ${ }^{4,14}$.

The limitations of this study include the small sample size which may be attributed to the number of patients who could justify the inclusion criteria within the time frame of the study. The study also has a relatively short follow-up.

\section{CONCLUSIONS}

Within the limitation of this study, we pointed out that abdominal autogenous fat seemed to be a better frontal sinus obliteration material compared to autogenous bone harvested from iliac crest, thanks to its lower donor site morbidity. However, we recommend further investigations with longer follow up periods to elucidate more about this topic.

\section{REFERENCES}

1. Koento T. Current advances in sinus preservation for the management of frontal sinus fractures. Curr Opin Otolaryngol Head Neck Surg. 2012 Aug;20(4):274-9.

2. Kalavrezos N. Current trends in the management of frontal sinus fractures. Injury. 2004 Apr;35(4):340-6.

3. Doonquah L, Brown P, Mullings W. Management of frontal sinus fractures. Oral Maxillofac Surg Clin North Am. 2012 May;24(2):265-74.

4. Manolidis S, Hollier LH Jr. Management of frontal sinus fractures. Plast Reconstr Surg. 2007 Dec;120(7 Suppl 2):32S-48S.

5. Ioannides $\mathrm{C}$, Freihofer HP. Fractures of the frontal sinus: classification and its implications for surgical treatment. Am J Otolaryngol 1999;20(5):273-80.

6. Gerbino, G., Roccia, F., Benech, A., and Caldarelli, C. Analysis of 158 frontal sinus fractures: Current surgical management and complications. J Craniomaxillofac Surg. 2000 Jun;28(3):133-9.

7. Tiwari P, Higuera S, Thornton J, Hollier LH. The management of frontal sinus fractures. J Oral Maxillofac Surg. 2005 Sep;63(9):1354-60.

8. Bell RB. Management of frontal sinus fractures. Oral Maxillofac Surg Clin North Am. 2009 May;21(2):227-42.

9. Yavuzer R, Sari A, Kelly CP, Tuncer S, Latifoglu O, Celebi MC, Jackson IT. Management of frontal sinus fractures. Plast Reconstr Surg. 2005 May;115(6):79e-93e.

10. Bell RB, Dierks EJ, Brar P, Potter JK, Potter BE. A protocol for the management of frontal sinus fractures emphasizing sinus preservation. J Oral Maxillofac Surg. 2007 May;65(5):825-39.

11. Rice DH. Management of frontal sinus fractures. Curr Opin Otolaryngol Head Neck Surg. 2004 Feb;12(1):46-8. 
12. Strong EB. Frontal sinus fracture. Oper Tech Otolaryngol Head Neck Surg. 2008;19:151-60.

13. Weathers WM, Wolfswinkel EM, Hatef DA, Lee EI, Brown RH, Hollier LH Jr. Frontal sinus fractures: a conservative shift. Send to Craniomaxillofac Trauma Reconstr. 2013 Sep;6(3):155-60.

14. Rohrich RJ, Hollier LH. Management of frontal sinus fractures. Changing concepts. Clin Plast Surg. 1992;19(1):21932.

15. Rodríguez IZ, Uceda MI, Lobato RD, Aniceto GS. Postraumatic frontal sinus obliteration with calvarial bone dust and demineralized bone matrix: a long term prospective study and literature review. Int J Oral Maxillofac Surg. 2013 Jan;42(1):71-6.

16. D'Addario M, Haug RH, Talwar RM. Biomaterials for use in frontal sinus obliteration. J Long Term Eff Med Implants. 2004;14(6):455-65.

17. Weber R, Draf W, Kahle G, and Kind M. Obliteration of the frontal sinus: State of the art and reflections on new materials. Rhinology. 1999 Mar;37(1):1-15.

18. Weber R, Draf W, Keerl R, Kahle G, Kind M, Schinzel S, Thomann S, Weber A. Magnetic resonance imaging following fat obliteration of the frontal sinus. Neuroradiology. 2002 Jan;44(1):52-8.

19. Peltola MJ, Aitasalo KM, Suonpaa JT, Yli-Urpo A, Laippala PJ, and Forsback AP. Frontal sinus and skull bone defect obliteration with three synthetic bioactive materials: A comparative study. J Biomed Mater Res B Appl Biomater. 2003 Jul 15;66(1):364-72.

20. Chouake RJ, Miles BA. Current opinion in otolaryngology and head and neck surgery: frontal sinus fractures. Curr Opin Otolaryngol Head Neck Surg. 2017 Aug;25(4):326331.

21. Weber R, Draf W, Keerl R, Kahle G, Schinzel S, Thomann $\mathrm{S}$, Lawson W. Osteoplastic frontal sinus surgery with fat obliteration: technique and long-term results using magnetic resonance imaging in 82 operations. Laryngoscope. 2000 Jun;110(6):1037-44.

22. Muminagic S, Masic T, Babajic E, Asotic M. Management of frontal sinus fracture: obliteration sinus with cancellous bone graft. Med Arh. 2011;65(4):250-1

23. Zubillaga Rodríguez I, Lora Pablos D, Falguera Uceda MI, Díez Lobato R, Sánchez Aniceto G. Frontal sinus obliteration after trauma: analysis of bone regeneration for two selected methods. Int J Oral Maxillofac Surg. 2014 Jul;43(7):827-33.

24. Shumrick KA, Smith CP. The use of cancellous bone for frontal sinus obliteration and reconstruction of frontal bony defects. Arch Otolaryngol Head Neck Surg. 1994 Sep;120(9):1003-9.
25. Zouhary KJ. Bone graft harvesting from distant sites: concepts and techniques. Oral Maxillofac Surg Clin North Am. 2010 Aug;22(3):301-16.

26. Ataç MS, Kilinç Y, Bozkaya S. Evaluation of bone graft harvesting techniques from anterior ilium. J Craniofac Surg. 2014 Jul;25(4):1418-21.

27. Mickel TJ, Rohrich RJ, Robinson JB. Frontal sinus obliteration: a comparison of fat, bone, muscle and spontaneous osteogenesis in the cat model. Plast Reconstr Surg. 1995 Mar;95(3):586-92.

28. Rodriguez ED, Stanwix MG, Nam AJ, St Hilaire H, Simmons OP, Christy MR, Grant MP, Manson PN. Twentysix-year experience treating frontal sinus fractures: a novel algorithm based on anatomical fracture pattern and failure of conventional techniques. Plast Reconstr Surg. 2008 Dec;122(6):1850-66.

29. Wichova H, Chiu AG, Villwock JA. Does the frontal sinus need to be obliterated following fracture with frontal sinus outflow tract injury? Laryngoscope. 2017 Sep;127(9):1967-9.

30. Donald PJ, Ettin M. The safety of frontal sinus fat obliteration when sinus walls are missing. Laryngoscope. 1986 Feb;96(2):190-3.

31. Bergara, AR, Itoiz, OA. Experimental study of the behavior of adipose tissue within the frontal sinus of the dog. Argent Rev Otorhinolaryngol. 1951;184:184-92.

32. Bergara AR, Itoiz AO. Present state of the surgical treatment of chronic frontal sinusitis. Arch Otolaryngol. 1955;61(6):616-28.

33. Fattahi T, Johnson C, Steinberg B. Comparison of 2 preferred methods used for frontal sinus obliteration. J Oral Maxillofac Surg. 2005 Apr;63(4):487-91.

34. Montgomery WW, and Pierce DL. Anterior osteoplastic fat obliteration for frontal sinus: Clinical experience and animal studies. Trans Am Acad Ophthalmol Otolaryngol. 1963;67: 46-57.

35. Montgomery WW. The fate of adipose implants in a bony cavity. Laryngoscope. 1964 Jun;74:816-27.

36. Goodale RL, Montgomery WW. Anterior Osteoplastic Frontal Sinus Operation: Five Years' Experience. Ann Otol Rhinol Laryngol. 1961 Sep;70:860-80.

37. Zonis RD, Montgomery WW, Goodale RL. Frontal sinus disease: 100 cases treated by osteoplastic operation. Laryngoscope. 1966 Nov;76(11):1816-25.

38. Hardy JM, Montgomery WW. Osteoplastic frontal sinusotomy: an analysis of 250 operations. Ann Otol Rhinol Laryngol. 1976 Jul-Aug;85(4 Pt 1):523-32. 